\title{
Bronchiectasis exacerbation study on
} azithromycin and amoxycillin-clavulanate for respiratory exacerbations in children (BEST-2): study protocol for a randomized controlled trial

Anne B Chang ${ }^{1,2,3^{*}}$, Keith Grimwood ${ }^{3,4}$, Andrew C Wilson ${ }^{5}$, Peter P van Asperen ${ }^{6}$, Catherine A Byrnes ${ }^{7}$, Kerry-Ann F O'Grady ${ }^{3}$, Theo P Sloots ${ }^{3,4}$, Colin F Robertson ${ }^{8}$, Paul J Torzillo9, Gabrielle B McCallum ${ }^{1}$, lan B Masters ${ }^{2,3}$, Helen M Buntain ${ }^{2,3}$, Ian M Mackay ${ }^{3,4}$, Jacobus Ungerer ${ }^{10}$, Joanne Tuppin ${ }^{2,3}$ and Peter S Morris ${ }^{1,11}$

\begin{abstract}
Background: Bronchiectasis unrelated to cystic fibrosis (CF) is being increasingly recognized in children and adults globally, both in resource-poor and in affluent countries. However, high-quality evidence to inform management is scarce. Oral amoxycillin-clavulanate is often the first antibiotic chosen for non-severe respiratory exacerbations, because of the antibiotic-susceptibility patterns detected in the respiratory pathogens commonly associated with bronchiectasis. Azithromycin has a prolonged half-life, and with its unique anti-bacterial, immunomodulatory, and anti-inflammatory properties, presents an attractive alternative. Our proposed study will test the hypothesis that oral azithromycin is non-inferior (within a 20\% margin) to amoxycillin-clavulanate at achieving resolution of non-severe respiratory exacerbations by day 21 of treatment in children with non-CF bronchiectasis.

Methods: This will be a multicenter, randomized, double-blind, double-dummy, placebo-controlled, parallel group trial involving six Australian and New Zealand centers. In total, 170 eligible children will be stratified by site and bronchiectasis etiology, and randomized (allocation concealed) to receive: 1) azithromycin ( $5 \mathrm{mg} / \mathrm{kg}$ daily) with placebo amoxycillin-clavulanate or 2) amoxycillin-clavulanate ( $22.5 \mathrm{mg} / \mathrm{kg}$ twice daily) with placebo azithromycin for 21 days as treatment for non-severe respiratory exacerbations. Clinical data and a parent-proxy cough-specific quality of life (PC-QOL) score will be obtained at baseline, at the start and resolution of exacerbations, and on day 21. In most children, blood and deep-nasal swabs will also be collected at the same time points. The primary outcome is the proportion of children whose exacerbations have resolved at day 21 . The main secondary outcome is the PC-QOL score. Other outcomes are: time to next exacerbation; requirement for hospitalization; duration of exacerbation, and spirometry data. Descriptive viral and bacteriological data from nasal samples and blood inflammatory markers will be reported where available.

(Continued on next page)
\end{abstract}

\footnotetext{
* Correspondence: annechang@ausdoctors.net

${ }^{1}$ Child Health Division, Menzies School of Health Research, Charles Darwin

University, Darwin, NT, Australia

${ }^{2}$ Queensland Children's Respiratory Centre, Royal Children's Hospital,

Brisbane, QLD, Australia

Full list of author information is available at the end of the article
} 
(Continued from previous page)

Discussion: Currently, there are no published randomized controlled trials (RCT) to underpin effective, evidencebased management of acute respiratory exacerbations in children with non-CF bronchiectasis. To help address this information gap, we are conducting two RCTs. The first (bronchiectasis exacerbation study; BEST-1) evaluates the efficacy of azithromycin and amoxycillin-clavulanate compared with placebo, and the second RCT (BEST-2), described here, is designed to determine if azithromycin is non-inferior to amoxycillin-clavulanate in achieving symptom resolution by day 21 of treatment in children with acute respiratory exacerbations.

Trial registration: Australia and New Zealand Clinical Trials Register (ANZCTR) number ACTRN12612000010897. http://www.anzctr.org.au/trial_view.aspx?id=347879

Keywords: Amoxycillin-clavulanate, Azithromycin, Bronchiectasis, Placebo, Pulmonary exacerbations, Randomized controlled trial

\section{Background}

Bronchiectasis unrelated to cystic fibrosis (CF) is an heterogenous condition with many initiating events. It is now considered more common than thought previously, especially in developing countries [1], in socioeconomically disadvantaged Indigenous communities in affluent countries [2] and as a co-morbidity of other chronic pulmonary diseases, such as asthma [3,4] and chronic obstructive pulmonary disease (COPD) [5]. Bronchiectasis affects all age groups, including infants [6]. Although the consequences of bronchiectasis are predominantly related to respiratory morbidity, there are also independent cardiovascular effects, such as coronary artery disease $[7,8]$, which are likely to worsen with the systemic inflammation arising from chronic pulmonary infection.

Over the past 15 to 20 years, it has been increasingly recognized that non-CF bronchiectasis is a major contributor to chronic respiratory morbidity $[9,10]$ and mortality [11,12] worldwide [2,13]. In our recently completed multicenter study of 346 Australian children newly referred for chronic cough and managed using a standardized protocol [14], 31 (9\%) had radiologically proven bronchiectasis [15]. In the USA, the average number of bronchiectasis-associated hospitalizations increased by 2 to 3\% per year between 1993 and 2006, and during this period, the average age-adjusted annual hospitalization rate was 16.5 per 100,000 of the population [9]. In some populations from affluent countries, the prevalence of bronchiectasis is one of the highest reported in the world, such as in Central Australia, where 1 in 68 Indigenous children are affected [16]. Similarly, in New Zealand, the estimated national prevalence rates of bronchiectasis are much higher in Maori (1 in 2300) and Pacific Island (1 in 625) children than in New Zealand European (1 in 7440) children aged under 15 years [17]. The minimum national incidence of nonCF bronchiectasis before the age of 15 years is 1 in 1,700 births, compared with 1 in 3,179 births for a diagnosis of CF in New Zealand [17]. In the European Union and the USA, the prevalence of CF is 7.4 to 7.9 per 100,000 (whole population data) [18]. Indeed, there are far more patients with bronchiectasis than patients with CF attending respiratory services globally [19]. In the US, about 30,000 [20] people have CF, whereas over 110,000 people have non-CF bronchiectasis [13]. Moreover, the latter is likely to be an underestimate, as many cases of non-CF bronchiectasis are misdiagnosed. or coexist with asthma [3,4,18] and COPD [5].

Effective clinical management reduces both short-term and long-term morbidity (and probably mortality) associated with bronchiectasis [1,21-23]. Cohort data have shown that about $80 \%$ of newly diagnosed adults (non-smokers) with bronchiectasis reported symptoms dating back to childhood, and that the duration of chronic cough (the most common symptom of bronchiectasis [24]) was related ( $\mathrm{r}=-0.51, P<0.001$ in nonsmokers) to lung function at diagnosis [25]. Arguably, appropriate overall management and treatment of exacerbations (leading to a reduction in persistent symptoms) potentially prevents or reduces deterioration of chronic respiratory disease [26]. Our study and a London-based retrospective study both found that with appropriate treatment in specialized centers, lung function improves and can be maintained [22,23]. However, despite substantial improvements, those with poor lung function at diagnosis were still likely to have poor lung function 5 years later [23]. We also found that the only significant predictor of decline in forced expiratory volume in 1 second $\left(\mathrm{FEV}_{1}\right)$ was the frequency of hospitalized exacerbations, and that $\mathrm{FEV}_{1}$ percentage predicted declined by $1.95 \%$ with each hospitalized exacerbation [23]. In addition to the biologic effects of respiratory exacerbations, these episodes also impair quality of life (QOL) and well-being. as shown by deteriorating scores for QOL and on the Depression, Anxiety and Stress Scale (DASS) during exacerbations [27]. Taken together, as airway injury in children is superimposed upon the physiological changes involving lung growth and development [28,29], we speculate that 
early and effective management of bronchiectasis exacerbations in children may lead to reduced hospitalizations, better QOL, and improved future adult lung function.

Although most respiratory physicians will treat acute exacerbations intensively with antibiotics and airway clearance $[24,30]$, some exacerbations are caused by viral infections, and may not require antibiotic therapy. However, it is possible that viral-bacterial interactions in the airways could promote or prolong endobronchial bacterial infection, which, with the accompanying inflammatory cascade, is a risk for additional lung injury [26,31]. To address whether antibiotics are superior to placebo at providing short-term clinical benefits, the first component of our Bronchiectasis Exacerbation Study (BEST), is a multicenter randomized controlled trial (RCT; BEST-1) designed to answer the question: 'Does azithromycin or amoxycillin-clavulanate, compared with placebo, improve the resolution of respiratory exacerbations on day 14 of treatment?' [32].

The second component of BEST (BEST-2) seeks to determine whether the two antibiotics used in BEST-1 are equivalent at achieving resolution of an acute respiratory exacerbation in children with bronchiectasis, compared with placebo. Based on available, but limited, data on the microbiology of lower-airway secretions in children with non-CF bronchiectasis [33], amoxycillin-clavulanate is currently recommended as the first-line empirical oral-antibiotic treatment for non-severe bronchiectasis exacerbations in children [24]. However, amoxycillinclavulanate requires dosing two to three times per day, and causes gastrointestinal symptoms in many children. Oral azithromycin is attractive as an alternative first-line therapy because of its long half-life, markedly reduced dosing schedule, and good safety profile in children [34]. Although azithromycin can be used 3 days/week [35] or even once weekly [36], our proposed study uses a daily dose in order to maintain effective blinding of the medications. However, if daily azithromycin is shown to be equivalent to amoxicillin-clavulanate, then extendedinterval azithromycin dosage schedules could be trialed in appropriate clinical settings where reduced dosing frequency is particularly appealing, such as for patients likely to have poor adherence.

As well as having anti-bacterial activity against most respiratory bacterial pathogens associated with non-CF bronchiectasis [37], azithromycin has additional antimicrobial properties that could prove beneficial. These include its unique bactericidal activity against intracellular strains of non-typeable Haemophilus influenzae [38], inhibitory effects upon biofilm formation [39], and anti-viral properties [40]. Furthermore, as a member of the macrolide class of antibiotics, it also has immunomodulatory and anti-inflammatory functions [41].
Given the emerging importance of both airway inflammation and biofilm development in the pathogenesis of acute and chronic respiratory disease [26,42], azithromycin may be a valuable intervention. Nevertheless, no RCTs have yet been carried out for azithromycin to help determine its role in treating acute exacerbations of bronchiectasis. Despite the lack of high-level evidence, azithromycin is sometimes used to treat adults with bronchiectasis exacerbations, perhaps as an extension of its reported positive effects on acute exacerbations of COPD [43]. By contrast, two RCTs of maintenance azithromycin therapy have been conducted in adults with non-CF bronchiectasis. One was a small, non-blinded, double cross-over RCT, where 6 months of azithromycin therapy was shown to improve lung function and reduce exacerbation frequency [44]. More recently, a 6-month, parallel, double-blind, placebocontrolled trial in New Zealand adults with bronchiectasis reported that azithromycin decreased exacerbation events, but did not alter lung function or QOL measures [45].

\section{Aims of the study}

In the second phase of BEST (BEST-2) the primary question will be: 'Is daily oral azithromycin non-inferior (within a $20 \%$ margin) to oral amoxycillin-clavulanate at achieving resolution of exacerbations by day 21 of treatment?'

The secondary aims are similar to those in BEST-1 [32], and are to: 1) determine the effect of azithromycin or amoxycillin-clavulanate on QOL, systemic inflammation, time to next respiratory exacerbation, and duration of exacerbations; 2) examine factors that predict response to the two antibiotics, including respiratory pathogens (viruses, bacteria, macrolide-resistant bacteria) present in respiratory secretions, and systemic markers of inflammation; and 3) describe, by using sensitive molecular detection techniques, the point prevalence and diversity of respiratory viruses and $\mathrm{Myco-}$ plasma pneumoniae and Chlamydiales species during exacerbations, compared with the findings at enrolment when the children are clinically stable.

The study will test the primary hypothesis that oral azithromycin is non-inferior (within a $20 \%$ margin) to oral amoxycillin-clavulanate at achieving resolution of respiratory exacerbations by day 21 of treatment in children with non-CF bronchiectasis.

\section{Methods}

\section{Study design}

We are conducting a multicenter, parallel group, doubledummy, double-blind placebo RCT (with concealed allocation) to assess whether oral azithromycin is noninferior to oral amoxycillin-clavulanate at treating 
children with a non-severe exacerbation of bronchiectasis. Our study plan is summarized in Figure 1.

\section{Eligibility}

The inclusion criteria are: age less than 19 years at time of enrolment; diagnosis of bronchiectasis by a respiratory physician following high-resolution computed tomography in the 5 years immediately prior to study entry, or if diagnosed earlier, evidence of regular follow-up by a respiratory physician for treatment of bronchiectasis; and more than two respiratory exacerbations in the 18 months prior to study entry. Children who have participated in BEST-1 [32] may participate subsequently in BEST-2. These children will be re-randomized for BEST-2.

Exclusion criteria are: current or recent severe exacerbation of bronchiectasis (dyspnea, hemoglobin desaturation $<90 \%$ in air or hospitalization) in the 8 weeks immediately prior to study entry; presence of CF or liver dysfunction; hypersensitivity to beta-lactam or macrolide antibiotics; current or recent (in the 4-months before study enrolment) lower-airway infection by a member of the Pseudomonas genus of gram-negative bacteria; receipt of beta-lactam or macrolide antibiotics within the 3 weeks preceding study entry; or current treatment for cancer.

\section{Recruitment}

Eligible children will be identified from clinics at one of six sites (Brisbane, Darwin, Melbourne Perth and Sydney in Australia, and Auckland in New Zealand). Parents will be approached, and informed consent obtained. Baseline pre-exacerbation data will be collected (Figure 1),

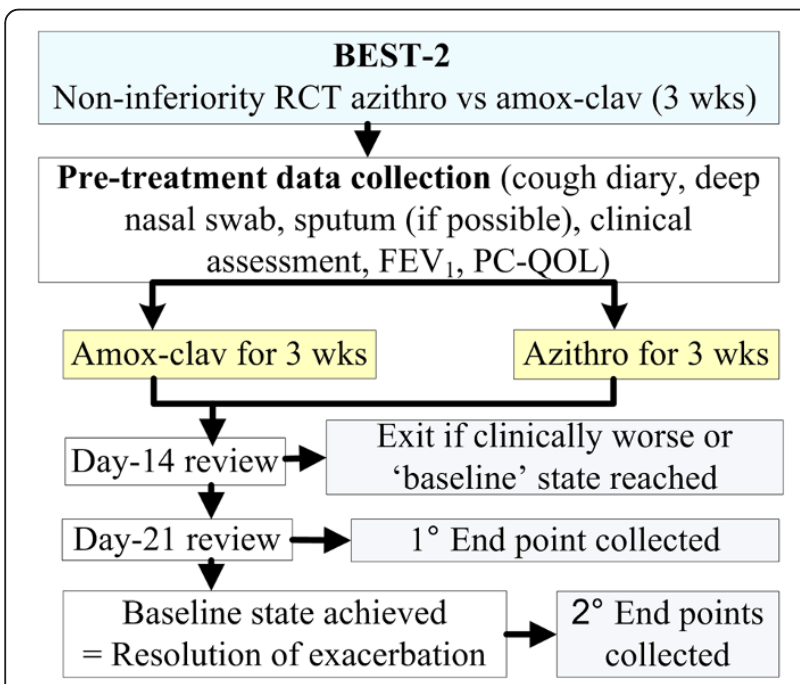

Figure 1 Overall schematic study design. Amox-clav, amoxycillinclavulanate; Azithro, azithromycin; BEST, Bronchiectasis Exacerbation Study. parents will be contacted monthly, and children will be reviewed every 3 months. Parents will be educated specifically on how to recognize the symptoms of an acute respiratory exacerbations, and asked to contact the research nurse at the onset of an exacerbation event.

\section{Intervention and follow-up}

A double-dummy design is planned. If eligibility is fulfilled, and after informed consent has been obtained, the child will be randomized to one of two arms. At the start of the exacerbation, the child will receive orally: 1) azithromycin with placebo amoxycillin-clavulanate or 2) amoxycillin-clavulanate with placebo azithromycin. The azithromycin dose is $5 \mathrm{mg} / \mathrm{kg} /$ day (to a maximum of $200 \mathrm{mg}$ daily, and for amoxycillin-clavulanate it is $22.5 \mathrm{mg} / \mathrm{kg} /$ dose twice daily (maximum $900 \mathrm{mg} / \mathrm{dose}$ ). Equivalent volumes of placebo will be given for both trial medications. All treatments will continue for 21 days.

An exacerbation is defined as an increase in sputum volume or purulence, or change in cough ( $>20 \%$ increase in cough score [46] or type (dry to wet) [47]) for more than 3 days. We validated this definition in our prospective study, and found that the kappa values (between clinicians) of these symptoms and signs were excellent $(>0.75)$ [48]. Daily diaries will also be collected during exacerbations until the scores for 2 or more days reflect the child's baseline state, which for each child will be established at enrolment, prior to any exacerbations. This assessment consists of a combination of symptoms (daily cough (yes/no), cough quality (wet/dry/none), cough score [46] averaged over two consecutive days) and signs (sputum color (if any present) using a color chart card (BronkoTest Ltd, London, UK), and crackles on chest auscultation). Children will be reviewed on days 14 and 21, and at resolution of the exacerbation. The exacerbation is considered resolved when symptoms and signs are the same as the baseline state. Postexacerbation, the children will be followed up and evaluated clinically every 3 months for a period of 18 months or until their next exacerbation (whichever is sooner). The time to next exacerbation will be determined by duration of days from the resolution of the current exacerbation to the beginning of the next exacerbation.

\section{Randomization, allocation, and blinding}

Upon enrolment, the child will be assigned to the next unique number on the appropriate stratified list. The allocation will be performed by the trial pharmacist at the Royal Children's Hospital (Brisbane, Australia). Randomization is stratified by site (Brisbane, Darwin, Melbourne, Perth, Sydney, Auckland), age ( $\leq 5$ or $>5$ years) and underlying etiology (idiopathic/post-pneumonia or all other causes). The randomization sequence is 
computer-generated and uses permuted blocks. The allocation sequence will be concealed at all times throughout the study. The computer-generated allocation sequence was prepared by a statistician external to the study team.

The specially manufactured placebo medications (Institute of Drug Technology Australia Ltd, Melbourne, Victoria, Australia), have a similar taste and color to their respective antibiotics. Both active medications (azithromycin and amoxycillin-clavulanate) will be repackaged and relabeled so that both antibiotics and their respective placebos are provided in identical opaque bottles. For all trial medications, equal volumes of water are added using a syringe and needle by punching the seal. Adherence will be assessed by parent report and return of empty bottles.

\section{Data collection}

All data will be recorded on standardized forms. On enrolment, demographic information (including age, gender, ethnicity, and household size), birth history, breast-feeding history, prior illness, and in utero and household smoke exposure, will be recorded, and a physical examination will be performed by a study physician. The primary and secondary outcome measures will be collected at the time points specified above. Serious and non-serious adverse effects (AEs: nausea, vomiting, diarrhea, rash) will also be documented and monitored. Safety exit points are discussed under 'End points' below.

\section{Specimen collection}

At enrolment (baseline) all children will have a deepnasal swab (NS) specimen collected. In a subset, additional specimens will be collected at baseline and during exacerbations, depending upon feasibility (some children may be unable to attend the study center at the onset of the exacerbation) and willingness of parents to allow additional NS collections and venepuncture procedures to be performed. These specimens are:

- A deep NS specimen for respiratory viruses, respiratory bacterial pathogens (including antibiotic susceptibility testing), and other potentially important respiratory pathogens (M. pneumoniae, Chlamydiales spp) at baseline, and at the beginning and resolution of an exacerbation. The techniques used are identical to previous studies [49-51], in which the specimens were described as nasopharyngeal swabs. In this study, we have elected to call these specimens 'deep-nasal swabs' as it is anatomically accurate to do so. The NS specimens will be handled in accordance with our research laboratory protocol (see below).
- Blood samples will be taken at baseline and at the beginning and end of each exacerbation for determination of $\mathrm{C}$-reactive protein (CRP), interleukin (IL)-6 (a neutrophilic marker of inflammation [52]), serum amyloid A (SAA) [48], and markers of viral infection (IL-10, interferon $\gamma$ inducible protein (IP)-10) [53].

- Sputum samples will also be taken at baseline and at the beginning and end of each exacerbation (when possible) for lower-airway microbiology cultures and antibiotic sensitivity tests.

\section{Further description of scores and laboratory methods Cough score}

The verbal categorical descriptive score is a validated daily diary score of cough rated on a six-point scale $(0$ (no cough) to 5 (severe cough and cannot perform usual activities)) with increasing scores reflecting greater interference with usual activities. This rating was validated against an objective cough-meter measure [46], and changes in cough scores have been shown to reflect changes in objective cough counts [54].

\section{Parent-proxy cough-specific quality of life score}

The parent-proxy cough-specific quality of life (PCQOL) score is a 27-item questionnaire designed to assess the level of frequency of feelings (15 items) and worry (12 items) related to their child's cough. It uses a seven-point Likert-type scale, with higher scores reflecting less frequency and fewer worry concerns (that is, greater QOL) $[55,56]$. The minimal important difference is 0.62 as determined by the distribution method, and 0.9 as determined by the anchor method [57].

\section{Bacteriology of nasal swab}

Compared with NS, oropharyngeal sampling underestimates Streptococcus pneumoniae carriage by approximately 50\% [58], Thus NS is the preferred method when evaluating the presence of antibiotic-resistant bacteria. Culturing, identifying, and when appropriate, serotyping common respiratory bacteria are established techniques in our research laboratory [51,59]. Swabs are stored in skim-milk tryptone-glucose-glycerol broth medium at $-80^{\circ} \mathrm{C}$, before being batch-processed for typical respiratory bacterial pathogens, notably $S$. pneumoniae, $H$. influenzae (including strains of non-typeable H. influenzae) and Moraxella catarrhalis. Batches of swabs are thawed, and $10 \mu \mathrm{L}$ aliquots cultured overnight on selective media at $37^{\circ} \mathrm{C}$ in $5 \% \mathrm{CO}_{2}$. Growth of $S$. pneumoniae, $H$. influenzae and $M$. catarrhalis is recorded and confirmed by standard techniques [51,60]. Two isolates each of S. pneumonia,H. influenzae and $M$. catarrhalis per positive swab are tested for anti-microbial resistance and stored $[51,60]$. S. pneumoniae isolates 
are serotyped using the Quellung method (antisera from Statens Serum Institute, Copenhagen, Denmark). Routine susceptibility testing using the calibrated dichotomous susceptibility disk-diffusion method. If the if the azithromycin disk annulus is less than $6 \mathrm{~mm}$ the minimum inhibitory concentration (MIC) of azithromycin will also be determined (Etests; AB Biodisk, Solna, Sweden). For $S$. pneumoniae, the penicillin MIC will be determined for penicillin non-susceptible isolates (oxacillin and/or penicillin disk annulus $<6 \mathrm{~mm}$ ) and for $H$. influenzae, the ampicillin MIC will be determined for ampicillin non-susceptible isolates (ampicillin disk annulus $<6 \mathrm{~mm}$ ). Interpretive criteria (Clinical and Laboratory Standards Institute breakpoints) used for $S$. pneumoniae are penicillin non-susceptible MIC greater $0.12 \mu \mathrm{g} / \mathrm{ml}$ and azithromycin resistance MIC $2 \mu \mathrm{g} / \mathrm{ml}$ or greater; and for $H$. influenzae, ampicillin resistance MIC 4. $\mu \mathrm{g} / \mathrm{ml}$ or greater and azithromycin resistance MIC greater than $4 \mu \mathrm{g} / \mathrm{ml}$. A nitrocephin-based test will identify betalactamase activity in $H$. influenzae and $M$. catarrhalis isolates.

\section{Assessment for viruses and other bacteria}

We will use our previously described methods of assessment [61,62]. Nucleic acids will be extracted from the media (High Pure Viral Nucleic Acid Kit; Roche Diagnostics, Sydney, NSW, Australia), in accordance with the manufacturer's instructions. Real-time PCR assays will be used to detect respiratory syncytial viruses (A and $B$ ), adenoviruses, influenza viruses (A and $B$ ), parainfluenza, human metapneumovirus, human coronaviruses (OC43, HK1, 229E, and NL63), enteroviruses, rhinoviruses (including determining specific rhinovirus genotypes by sequencing the VP4-VP2 region [63]) and the more recently described human viruses (human bocavirus 1, parechoviruses, and human polyomaviruses $\mathrm{K} 1$ and WU) and $M$. pneumoniae and Chlamydiales species [64].

\section{Blood markers}

CRP, threshold $5 \mathrm{mg} / \mathrm{l}$ ) are standard tests that will be analyzed by the Diagnostic Laboratories of each participating center. SAA, IL-6 (threshold $<3 \mathrm{pg} / \mathrm{ml}$ ), IL-10 (threshold $<0.5 \mathrm{pg} / \mathrm{ml}$ ) and IP-10, (threshold $2.8 \mathrm{pg} / \mathrm{ml}$ ) will be performed by commercial enzyme immunoassay kits (R\&D Systems, Minneapolis, USA) at our research laboratory.

Spirometry (in children aged $\geq 5$ years) will be performed using American Thoracic Society criteria and the recorded $\mathrm{FEV}_{1} \%$ predicted. We elected not to use oscillatory measures, as we previously found no difference in airway resistance between steady and exacerbation states [48]. Thus, we will use conventional spirometry, although we do not expect to detect significant differences.

\section{End points}

Participation will be complete when the child's clinical state returns to baseline and the time to next exacerbation has been obtained. Other exit points are: if the child deteriorates during treatment prior to day 21, or becomes sufficiently intolerant of the trial medications to require withdrawal from the study (as determined by the treating clinician).

\section{Outcome measures \\ Primary outcome}

The primary outcome will be the proportion of children whose exacerbations have resolved by day 21 of treatment. Exacerbations will be considered resolved when symptoms and signs are the same as the baseline state. Children who are withdrawn from the study, or receive additional antibiotic treatment, will be categorized as non-resolved.

\section{Secondary clinical outcomes}

The main secondary outcome is the PC-QOL score. Other outcomes are 1) the time to next exacerbation; 2) requirement for hospitalization; 3) duration of exacerbation (persistence of symptoms till return to baseline state); and 4) $\mathrm{FEV}_{1} \%$ predicted.

\section{Secondary laboratory outcomes}

Serum markers (CRP, SAA, IL-6, IL-10, IP-10) and data on viruses and respiratory bacterial pathogens, including their antibiotic susceptibility to penicillin and azithromycin.

\section{Sample size}

We plan to enroll 170 children (85 per arm), providing $90 \%$ power $(\alpha=0.05,1$-sided) with $20 \%$ non-inferiority margin to detect $80 \%$ resolution rate by day 21 . The margin selected is relatively large in statistical terms, but the physicians considered it clinically appropriate. As the primary outcome will be obtained in all enrolled children, retention fraction has not been factored in for the intention-to-treat analysis.

The main secondary outcome (secondary aim 1) is PC-QOL. Based on a non-inferiority limit of 0.9 (minimum important difference [57]) and standard deviation of 0.9 , our sample size provides a power of $99.9 \%(\alpha=$ 0.05 , one-sided $95 \% \mathrm{CI}$ ) for data from at least 136 children (assuming at least $80 \%$ retention of children enrolled). For secondary aim 2 (see list under 'Aims of the study'), we will be examining eight main factors, and thus a sample size of 136 exceeds the recommended minimum ( $n=10$ per factor) [65]. The eight factors are: 
smoking, age, underlying etiology, detection of virus (any versus none, then single versus multiple viruses), presence of azithromycin resistance, and levels of various blood markers (IL-6, IL-10, IP-10).

\section{Statistical analysis and reporting}

Data will be reported and presented in accordance with the updated Consolidated Standards of Reporting Trials (CONSORT) criteria [66]. Children will be analyzed in accordance with allocation status (regardless of subsequent management).

For our primary aim, the main effects of the interventions will be determined by comparing the primary outcome (resolution of exacerbation) between groups (azithromycin versus amoxicillin-clavulanate). Children who exit the study as 'clinically worse' or 'drop-out' before the end point is reached will be considered as 'non-resolved'. Those who exit the study as 'returned to baseline' will be considered as 'resolved'. Odds ratios will be calculated and, if appropriate, the number needed to treat (for benefit) will be expressed. Per-protocol analysis will be an a priori secondary analysis.

\section{Statistical analysis for secondary outcomes and aims}

For the clinical secondary outcome (secondary aim 1), the $t$-test or the Mann-Whitney test will be used for continuous variables (depending on normality of data distribution). A Kaplan-Meier curve will be constructed for each group for time to resolution and time to next exacerbation, as reported previously [67]. For secondary aim 2 (factors that predict response to antibiotics), univariate analyses will be used to examine several biologic factors (for example, smoking, age, ethnicity, underlying etiology, detection of virus (any versus none, then single versus multiple viruses), presence of azithromycin resistance, and levels of blood markers (IL6, IL-10, IP-10)). Factors with $P<0.2$ will be included in a logistic regression model. Potential interactions (for example,. between viruses and bacteria) will be examined in the model. Descriptive data will be used for secondary aim 3 (point prevalence of respiratory pathogens).

\section{Data safety monitoring committee}

A Data Safety Monitoring Committee has been established and met prior to commencement of this study.

\section{Ethics approval}

The protocol has received ethics approval from the respective Human Research Ethics Committees of all the participating institutions (Brisbane: Children's Health Queensland Hospital and Health Service (Royal Children's Hospital) and University of Queensland; Darwin:
Department of Health and Families and Menzies School of Health Research; Melbourne: Royal Children's Hospital; Perth: Princess Margaret Hospital; Sydney: Sydney Children's Hospital Network Human Research Ethics Committee; and Auckland: Northern Ethics Committee, Ministry of Health and Starship Children's Health local ethics committee). The study is being conducted under Australia's Therapeutic Goods Administration Clinical Trial Notification (CTN) scheme.

\section{Discussion}

In addition to the increased recognition over the past 20 years of the disease burden from bronchiectasis, the need for more effective treatment is also reflected by 1 ) the association of the disease with other chronic pulmonary disorders; 2) its adverse effect on QOL and other co-morbidities; and 3) its influence on lungfunction decline and mortality [68].

However, despite the considerable global burden of bronchiectasis and the importance of exacerbations [68], there are no published RCTs on the management of bronchiectasis exacerbations in children [69]. Bronchiectasis is often considered a neglected disease, and services to manage people with bronchiectasis receive disproportionately fewer allocated resources (both clinical and research), compared with other chronic pulmonary disorders [10,70,71]. Almost all current recommendations are based on management of CF $[24,30]$, and such extrapolation can, on occasions, be detrimental for those with non-CF bronchiectasis. For example, a large RCT found that deoxyribonuclease (efficacious for CF) increased exacerbations and accelerated the decline in $\mathrm{FEV}_{1}$ in adults with bronchiectasis [72], despite previous case reports advocating its use [73].

In asthma [61], CF [74] and COPD [75,76], viral triggers of acute exacerbations are well described; however, no such data exist for non-CF bronchiectasis. Whether other potential respiratory pathogens ( $M$. pneumoniae and Chlamydiales species) trigger exacerbations is also unknown. Our retrospective study found that $34 \%$ of exacerbations were preceded by a viral-like illness [77]. Thus, for the first time in this population, BEST-1 [32] and BEST-2 will both determine the nature and diversity of respiratory viruses and $M$. pneumoniae and Chlamydia species associated with bronchiectasis exacerbations, and compare these results with those obtained at baseline, to help determine attributable risk.

The 20\% margin used for our study, although relatively large, was deemed clinically appropriate, given the potential major advantage of future once-weekly dosing with azithromycin compared with twice-daily dosing wit amoxycillin-clavulanate. In disadvantaged communities, adult-supervised twice-daily dosing is not always possible, 
and may result in children with exacerbations receiving suboptimal treatment. By contrast, once-weekly dosing is feasible with weekly home or clinic visits; we have achieved this outcome in studies involving remote Indigenous settings in Australia [50] and in New Zealand [78]. Thus, if non-inferiority between amoxycillin-clavulanate and azithromycin is established, this would provide an easier option for managing exacerbations, and could substantially improve adherence in disadvantaged settings.

\section{Rationale for our chosen outcome measures and timeframe}

In BEST-1, we chose day 14 as the time point for this RCT, based on available data from our retrospective data of 115 respiratory exacerbations [77], and on parental and healthcare professional concerns over using placebo for an extended period [32]. For BEST-2, presented here, we chose day 21 as the crucial time point because hospitalization is usually recommended if there is no symptomatic improvement after 3 to 5 weeks of oralantibiotic therapy.

Adult bronchiectasis studies show that QOL measures, particularly cough-specific QOL indices, are valid and important outcome measures [79,80]. Likewise, we have previously shown the utility of the PC-QOL score in children with bronchiectasis [27].

\section{Conclusion}

Our study addresses a large knowledge gap in an underresearched area [71]. Our multi-center, double-blind, double-dummy, RCT, which examines the non-inferiority of azithromycin compared with amoxycillin-clavulanate for acute non-severe exacerbations of bronchiectasis in children has the potential to simplify the management of these exacerbations, thus possibly achieving both shortterm gains and a long-term benefit for reducing the morbidity of bronchiectasis. Conclusive results will strengthen evidence-based, standard treatment guidelines.

\section{Trial status}

Recruitment for BEST-1 [32] started in mid-March 2012 in Darwin, and in June 2012 in Brisbane. Randomization for the BEST-2 component commenced in October 2012 in Brisbane and Darwin.

\section{Abbreviations \\ BEST: Bronchiectasis Exacerbation Study; CF: Cystic fibrosis; COPD: Chronic obstructive pulmonary disease; CRP: C-reactive protein; FEV ${ }_{1}$ : Forced expiratory volume in 1 second; IL: Interleukin; IP: Interferon $\mathrm{Y}$-inducible protein; MIC: Minimum inhibitory concentration; NS: Nasal swab; PC- QOL: Parent-proxy cough-specific quality of life; PCR: Polymerase chain reaction; QOL: Quality of life; RCT: Randomized controlled trial; SAA: Serum amyloid $\mathrm{A}$}

\section{Competing interests}

The authors declare that they have no financial competing interests related to this study.

\section{Authors' contributions}

AC conceived the study, participated in its design and coordination, and drafted the manuscript. PM, CR, KG, PVA, AW, KO, PT, TS participated in study design and submission to the National Health and Medical Research Council (NHMRC). GM participated in initiating the project, and TS and IMM participated in the viral analysis plan. IBM, CB, and $\mathrm{HB}$ will assist in recruitment and assessment of the children. $J U$ will participate in the biochemical analysis of the blood samples. All authors have read and approved the final manuscript.

\section{Acknowledgements}

We thank the research staff (Lesley Versteegh, Clare Wilson, Sophie Anderson-James, Emily Bailey, Helen Petsky) for facilitating the study, Robert Ware for generating the randomization sequences,and Anita Champion for allocating the children and dispensing the medications. We are also grateful to members of the Indigenous Reference Group of the Child Health Division at Menzies for supporting this study and for over-seeing the cultural aspects. We also thank Professor Alan Isles, Professor Craig Mellis, A/Professor Chris Blyth, and Mr Mark Chatfield for voluntarily providing their time in their participation as members of the safety data monitoring committee.

\section{Funding}

The study is funded by a 3-year Australian NHMRC project grant (number 1019834) and supported by a NHMRC Centre for Research Excellence in Lung Health of Aboriginal and Torres Strait Islander Children (grant number 1040830). AC (grant number 545216) is supported by NHMRC practitioner fellowship. KOG is supported by funding from the Children's Health Foundation Queensland, Queensland Government Smart Futures fellowship (number 51008) and NHMRC Career Development Fellowship (number 1045157). The views expressed in this publication are those of the authors, and do not reflect the views of the NHMRC.

\section{Author details}

${ }^{1}$ Child Health Division, Menzies School of Health Research, Charles Darwin University, Darwin, NT, Australia. ${ }^{2}$ Queensland Children's Respiratory Centre, Royal Children's Hospital, Brisbane, QLD, Australia. ${ }^{3}$ Queensland Children's Medical Research Institute, Brisbane, QLD, Australia. ${ }^{4}$ Queensland Paediatric Infectious Diseases Laboratory, Royal Children's Hospital, Brisbane, QLD, Australia. ${ }^{5}$ Department of Respiratory Medicine, Princess Margaret Hospital, Perth, Australia. ${ }^{6}$ Department of Respiratory Medicine, The Children's Hospital at Westmead and Sydney Medical School, University of Sydney, Sydney, NSW, Australia. ${ }^{7}$ Department of Paediatrics, University of Auckland and Starship Children's Hospital, Auckland, New Zealand. ${ }^{8}$ Department of Respiratory Medicine, Royal Children's Hospital, Murdoch Children's Research Institute, University of Melbourne, Melbourne, VIC, Australia. ${ }^{9}$ Royal Prince Alfred Hospital, Sydney, Australia. ${ }^{10}$ Department Chemical Pathology, Queensland Pathology, Royal Brisbane Hospital, Brisbane, Australia.

${ }^{11}$ Department of Paediatrics, Royal Darwin Hospital, Darwin, NT, Australia.

Received: 4 October 2012 Accepted: 22 January 2013

Published: 20 February 2013

\section{References}

1. Dogru D, Nik-Ain A, Kiper N, Gocmen A, Ozcelik U, Yalcin E, Aslan AT: Bronchiectasis: the consequence of late diagnosis in chronic respiratory symptoms. J Trop Pediatr 2005, 51:362-365.

2. Chang AB, Grimwood K, Macguire G, King PT, Morris PS, Torzillo PJ: Management of bronchiectasis and chronic suppurative lung disease (CSLD) in Indigenous children and adults from rural and remote Australian communities. Med J Aust 2008, 189:386-393.

3. Donnelly DE, Critchlow A, Everard ML: Outcomes in children treated for persistent bacterial bronchitis. Thorax 2007, 62:80-84

4. Gupta S, Siddiqui S, Haldar P, Raj JV, Entwisle JJ, Wardlaw AJ, Bradding P, Pavord ID, Green RH, Brightling CE: Qualitative analysis of high resolution computed tomography scans in severe asthma. Chest 2009, 136:1521-1528.

5. O'Brien C, Guest PJ, Hill SL, Stockley RA: Physiological and radiological characterisation of patients diagnosed with chronic obstructive pulmonary disease in primary care. Thorax 2000, 55:635-642. 
6. O'Grady KA, Torzillo PJ, Chang AB: Hospitalisation of Indigenous children in the Northern Territory for lower respiratory illness in the first year of life. Med J Aust 2010, 192:586-590.

7. Simons L, Simons J, Friedlander Y, McCallum J: Chronic bronchitis and risk of coronary heart disease. Lancet 1996, 348:1388-1389.

8. Kiechl S, Egger G, Mayr M, Wiedermann CJ, Bonora E, Oberhollenzer F, Muggeo M, Xu Q, Wick G, Poewe W, Willeit J: Chronic infections and the risk of carotid atherosclerosis: prospective results from a large population study. Circulation 2001, 103:1064-1070.

9. Seitz AE, Olivier KN, Steiner CA, De Oca RM, Holland SM, Prevots DR: Trends and burden of bronchiectasis-associated hospitalizations: USA, 19932006. Chest 2010, 138:944-949.

10. Santamaria F, Montella S, Pifferi M, Ragazzo V, De SS, De PN, Maglione M, Boner AL: A descriptive study of non-cystic fibrosis bronchiectasis in a pediatric population from central and southern Italy. Respiration 2009, 77:160-165.

11. Roberts HJ, Hubbard R: Trends in bronchiectasis mortality in England and Wales. Respir Med 2010, 104:981-985

12. Steinfort DP, Brady S, Weisinger HS, Einsiedel L: Bronchiectasis in Central Australia: a young face to an old disease. Respir Med 2008, 102:574-578.

13. Weycker D, Edelsberg J, Oster G, Tino G: Prevalence and economic burden of bronchiectasis. Clin Pulm Med 2005, 12:205-209.

14. Chang AB, Robertson CF, van Asperen PP, Glasgow NJ, Masters IB, Mellis CM, Landau LI, Teoh L, Morris PS: Can a management pathway for chronic cough in children improve clinical outcomes: protocol for a multicentre evaluation. Trials 2010, 11:103.

15. Chang $A B$, Robertson CF, van Asperen PP, Glasgow NJ, Mellis CM, Masters IB, Teoh L, Tjhung I, Morris PS, Petsky HL, Willis C, Landau LI: A multi-centre study on chronic cough in children: burden and etiologies based on a standardized management pathway. Chest 2012, epub ahead Mar 29.

16. Chang AB, Masel JP, Boyce NC, Wheaton G, Torzillo PJ: Non-CF bronchiectasis-clinical and HRCT evaluation. Pediatr Pulmonol 2003, 35:477-483

17. Twiss J, Metcalfe R, Edwards EA, Byrnes C: New Zealand national incidence of bronchiectasis "too high" for a developed country. Arch Dis Child 2005, 90:737-740.

18. Farrell PM: The prevalence of cystic fibrosis in the European Union. J Cyst Fibros 2008, 7:450-453.

19. Chang AB: Editorial. Bronchiectasis: so much yet to learn and to do. Paediatr Respir Rev 2011, 12:89-90.

20. Cystic Fibrosis Foundation, Frequently Asked Questions. [http://www.cff.org/ AboutCF/Faqs] Accessed 24 December 2010.

21. Haidopoulou K, Calder A, Jones A, Jaffe A, Sonnappa S: Bronchiectasis secondary to primary immunodeficiency in children: longitudinal changes in structure and function. Pediatr Pulmonol 2009, 44:669-675.

22. Bastardo CM, Sonnappa S, Stanojevic S, Navarro A, Lopez PM, Jaffe A, Bush A: Non-cystic fibrosis bronchiectasis in childhood: longitudinal growth and lung function. Thorax 2009, 64:246-251.

23. Kapur N, Masters IB, Chang AB: Longitudinal growth and lung function in pediatric non-CF bronchiectasis - what influences lung function stability? Chest 2010, 138:158-164.

24. Chang AB, Bell SC, Byrnes CA, Grimwood K, Holmes PW, King PT, Kolbe J Landau LI, Maguire GP, McDonald MI, Reid DW, Thien FC, Torzillo PJ: Bronchiectasis and chronic suppurative lung disease (CSLD) in children and adults in Australian and New Zealand: thoracic society of Australia and New Zealand and Australian lung foundation position statement. Med J Aust 2010, 193:356-365.

25. King PT, Holdsworth SR, Farmer M, Freezer N, Villanueva E, Holmes PW Phenotypes of adult bronchiectasis: onset of productive cough in childhood and adulthood. COPD 2009, 6:130-136.

26. Chang $A B$, Byrnes $C A$, Everard ML: Diagnosing and preventing chronic suppurative lung disease (CSLD) and bronchiectasis. Paediatr Respir Rev 2011, 12:97-103.

27. Kapur N, Masters IB, Newcombe P, Chang AB: The burden of disease in pediatric non-cystic fibrosis bronchiectasis. Chest 2012, 141:1018-1024.

28. Chang AB: Pediatric cough: children are not miniature adults. Lung 2010 188:S33-S40.

29. Chang $A B$, Redding GJ, Everard ML: State of the Art - Chronic wet cough: protracted bronchitis, chronic suppurative lung disease and bronchiectasis. Pediatr Pulmonol 2008, 43:519-531.
30. Pasteur MC, Bilton D, Hill AT: British thoracic society guideline for non-CF bronchiectasis. Thorax 2010, 65:i1-i58.

31. Cole PJ: Inflammation: a two edged sword. The model of bronchiectasis Eur J Respir Dis Suppl 1986, 147:6-15.

32. Chang AB, Grimwood K, Wilson A, van Asperen PP, O'Grady KA, Robertson CF, Sloots TP, Torzillo PJ, Bailey EJ, McCallum GB, Masters IB, Byrnes CA Chatfield MD, Buntain H, Mackay IM, Morris PS: Randomised placebocontrolled trial on antibiotics for bronchiectasis exacerbations in children: rationale and protocol. Trials 2012, 13:156.

33. Grimwood K: Airway microbiology and host defenses in paediatric nonCF bronchiectasis. Paediatr Respir Rev 2011, 12:111-118.

34. Morris PS, Gadil G, McCallum GB, Wilson CA, Smith-Vaughan HC, Torzillo P, Leach AJ: Single-dose azithromycin versus seven days of amoxycillin in the treatment of acute otitis media in Aboriginal children (AATAAC): a double blind, randomised controlled trial. Med J Aust 2010, 192:24-29.

35. Saiman L, Anstead M, Mayer-Hamblett N, Lands LC, Kloster M, HocevarTrnka J, Goss CH, Rose LM, Burns JL, Marshall BC, Ratjen F: Effect of azithromycin on pulmonary function in patients with cystic fibrosis uninfected with Pseudomonas aeruginosa: a randomized controlled trial. JAMA 2010, 303:1707-1715.

36. Steinkamp G, Schmitt-Grohe S, Doring G, Staab D, Pfrunder D, Beck G, Schubert R, Zielen S: Once-weekly azithromycin in cystic fibrosis with chronic Pseudomonas aeruginosa infection. Respir Med 2008, 102:1643-1653.

37. Kapur N, Grimwood K, Masters IB, Morris PS, Chang AB: Lower airway microbiology and cellularity in children with newly diagnosed non-CF bronchiectasis. Pediatr Pulmonol 2012, 47:300-307.

38. Hotomi M, Arai J, Billal DS, Takei S, Ikeda Y, Ogami M, Kono M, Beder LB, Toya K, Kimura M, Yamanaka N: Nontypeable Haemophilus influenzae isolated from intractable acute otitis media internalized into cultured human epithelial cells. Auris Nasus Larynx 2010, 37:137-144.

39. Starner TD, Shrout JD, Parsek MR, Appelbaum PC, Kim GH: Subinhibitory concentrations of azithromycin decrease nontypeable haemophilus influenzae biofilm formation and diminish established biofilms. Antimicrob Agents Chemother 2008, 52:137-145.

40. Gielen V, Johnston SL, Edwards MR: Azithromycin induces anti-viral responses in bronchial epithelial cells. Eur Respir J 2010, 36:646-654.

41. Giamarellos-Bourboulis EJ: Macrolides beyond the conventional antimicrobials: a class of potent immunomodulators. Int J Antimicrob Agents 2008, 31:12-20.

42. Kramer BW, Kallapur S, Newnham J, Jobe AH: Prenatal inflammation and lung development. Semin Fetal Neonatal Med 2009, 14:2-7.

43. Milstone AP: Use of azithromycin in the treatment of acute exacerbations of COPD. Int J Chron Obstruct Pulmon Dis 2008, 3:515-520.

44. Cymbala AA, Edmonds LC, Bauer MA, Jederlinic PJ, May JJ, Victory JM, Amsden GW: The disease-modifying effects of twice-weekly oral azithromycin in patients with bronchiectasis. Treat Respir Med 2005, 4:117-122.

45. Wong C, Jayaram L, Karalus N, Eaton T, Tong C, Hockey H, Milne D, Fergusson W, Tuffery C, Sexton P, Storey L, Ashton T: Azithromycin for prevention of exacerbations in non-cystic fibrosis bronchiectasis (EMBRACE): a randomised, double-blind, placebo-controlled trial. Lancet 2012, 380:660-667.

46. Chang AB, Newman RG, Carlin J, Phelan PD, Robertson CF: Subjective scoring of cough in children: parent-completed vs child-completed diary cards vs an objective method. Eur Respir J 1998, 11:462-466.

47. Chang AB, Eastburn MM, Gaffney J, Faoagali J, Cox NC, Masters IB: Cough quality in children: a comparison of subjective vs. bronchoscopic findings. Respir Res 2005, 6:3.

48. Kapur N, Masters IB, Morris PS, Galligan J, Ware R, Chang AB: Defining pulmonary exacerbation in children with non-cystic fibrosis bronchiectasis. Pediatr Pulmonol 2012, 47:68-75.

49. Leach AJ, Boswell JB, Asche V, Nienhuys TG, Mathews JD: Bacterial colonization of the nasopharynx predicts very early onset and persistence of otitis media in Australian aboriginal infants. Pediatr Infect Dis J 1994, 13:983-989.

50. Chang AB, Grimwood K, White AV, Maclennan C, Sloots TP, Sive A, McCallum GB, Mackay IM, Morris PS: Randomized placebo-controlled trial on azithromycin to reduce the morbidity of bronchiolitis in Indigenous Australian infants: rationale and protocol. Trials 2011 12:94. 
51. Hare KM, Grimwood K, Leach AJ, Smith-Vaughan HC, Torzillo PJ, Morris P, Chang $A B$ : Respiratory bacterial pathogens in the nasopharynx and lower airways of Australian Indigenous children with bronchiectasis. J Pediatr 2010, 157:1001-1005.

52. Wood LG, Scott HA, Garg ML, Gibson PG: Innate immune mechanisms linking non-esterified fatty acids and respiratory disease. Prog Lipid Res 2009, 48:27-43.

53. Wood LG, Simpson JL, Wark PA, Powell H, Gibson PG: Characterization of innate immune signalling receptors in virus-induced acute asthma. Clin Exp Allergy 2011, 41:640-648.

54. Chang AB, Phelan PD, Robertson CF, Roberts RDG, Sawyer SM: Relationship between measurements of cough severity. Arch Dis Child 2003, 88:57-60.

55. Newcombe PA, Sheffield JK, Juniper EF, Halstead RA, Masters IB, Chang AB: Development of a parent-proxy quality-of-life chronic cough-specific questionnaire: clinical impact vs psychometric evaluations. Chest 2008 133:386-395.

56. Newcombe PA, Sheffield JK, Juniper EF, Petsky HL, Willis C, Chang AB: Validation of a parent-proxy quality-of-life questionnaire (PC-QOL) for paediatric chronic cough. Thorax 2010, 65:819-823.

57. Newcombe PA, Sheffield JK, Chang AB: Minimally important change in a parent-proxy quality of life questionnaire for pediatric chronic cough (PC-QOL). Chest 2010, 139:576-580.

58. Watt JP, O'Brien KL, Katz S, Bronsdon MA, Elliott J, Dallas J, Perilla MJ, Reid R, Murrow L, Facklam R, Santosham M, Whitney CG: Nasopharyngeal versus oropharyngeal sampling for detection of pneumococcal carriage in adults. J Clin Microbiol 2004, 42:4974-4976.

59. Stubbs E, Hare K, Wilson C, Morris P, Leach AJ: Streptococcus pneumoniae and noncapsular Haemophilus influenzae nasal carriage and hand contamination in children: a comparison of two populations at risk of otitis media. Pediatr Infect Dis J 2005, 24:423-428.

60. Hare KM, Morris P, Smith-Vaughan H, Leach AJ: Random colony selection versus colony morphology for detection of multiple pneumococcal serotypes in nasopharyngeal swabs. Pediatr Infect Dis J 2008, 27:178-180.

61. Arden KE, Chang AB, Lambert SB, Nissen M, Sloots TP, Mackay IM: Newly identified respiratory viruses in children with asthma exacerbation not requiring admission into hospital. J Med Virology 2010, 82:1458-1461.

62. Syrmis MW, Whiley DM, Thomas M, Mackay IM, Williamson J, Siebert DJ, Nissen MD, Sloots TP: A sensitive, specific, and cost-effective multiplex reverse transcriptase-PCR assay for the detection of seven common respiratory viruses in respiratory samples. J Mol Diagn 2004, 6:125-131.

63. McErlean P, Shackelton LA, Andrews E, Webster DR, Lambert SB, Nissen MD, Sloots TP, Mackay IM: Distinguishing molecular features and clinical characteristics of a putative new rhinovirus species, human rhinovirus $\mathrm{C}$ (HRV C). PLoS One 2008, 3:e1847.

64. Wisdom A, Leitch EC, Gaunt E, Harvala H, Simmonds P: Screening respiratory samples for detection of human rhinoviruses (HRVs) and enteroviruses: comprehensive VP4-VP2 typing reveals high incidence and genetic diversity of HRV species C. J Clin Microbiol 2009, 47:3958-3967.

65. Altman DG: Relation between several variables. In Practical Statistics for Medical Research. Edited by. London: Chapman \& Hall; 1991:326-364.

66. Schulz KF, Altman DG, Moher D: CONSORT 2010 Statement: updated guidelines for reporting parallel group randomised trials. Trials 2010, 11:32.

67. Chang AB, Torzillo PJ, Boyce NC, White AV, Stewart PA, Wheaton GR, Purdie DM, Wakerman J, Valery PC: Zinc and vitamin-A supplementation in Indigenous children hospitalised with episodes of lower respiratory tract infection: a randomised controlled trial. Med J Aust 2006, 184:107-112.

68. Chang $A B$, Marsh RL, Smith-Vaughan HC, Hoffman LR: Emerging drugs for bronchiectasis. Expert Opin Emerg Drugs 2012, 17:361-78.

69. Wurzel D, Marchant JM, Yerkovich ST, Upham JW, Masters IB, Chang AB: Short courses of antibiotics for children and adults with bronchiectasis. Cochrane Database Syst Rev 2011, 6:CD008695.

70. Kolbe J, Wells AU: Bronchiectasis: a neglected cause of respiratory morbidity and mortality. Respirology 1996, 1:221-225.

71. Tsang KW, Bilton D: Clinical challenges in managing bronchiectasis. Respirology 2009, 14:637-650.

72. O'Donnell AE, Barker AF, llowite JS, Fick RB: Treatment of idiopathic bronchiectasis with aerosolized recombinant human DNase I. rhDNase Study Group. Chest 1998, 113:1329-1334.
73. Desai M, Weller PH, Spencer DA: Clinical benefit from nebulized human recombinant DNase in Kartagener's syndrome. Pediatr Pulmonol 1995, 20:307-308

74. Wark $P A B$, Tooze $M$, Cheese $L$ : Viral infections trigger exacerbations of cystic fibrosis in adults and children. Eur Respir J 2012, 40:510-512.

75. Proud D, Chow CW: Role of viral infections in asthma and chronic obstructive pulmonary disease. Am J Respir Cell Mol Biol 2006, 35:513-518.

76. Hutchinson AF, Black J, Thompson MA, Bozinovski S, Brand CA, Smallwood DM, Irving LB, Anderson GP: Identifying viral infections in vaccinated chronic obstructive pulmonary disease (COPD) patients using clinical features and inflammatory markers. Influenza Other Respir Viruses 2010, 4:33-39.

77. Kapur N, Masters IB, Chang AB: Exacerbations in non cystic fibrosis bronchiectasis: clinical features and investigations. Respir Med 2009, 103:1681-1687.

78. Valery PC, Morris PS, Grimwood K, Torzillo PJ, Byrnes CA, Masters IB, Bauert $P$, McCallum GB, Mobberly C, Chang AB: Azithromycin for Indigenous children with bronchiectasis: study protocol for a multi-centre randomized controlled trial. BMC Pediatr 2012, 12:122.

79. Courtney JM, Kelly MG, Watt A, Garske L, Bradley J, Ennis M, Elborn JS: Quality of life and inflammation in exacerbations of bronchiectasis. Chron Respir Dis 2008, 5:161-168.

80. Murray MP, Turnbull K, Macquarrie S, Hill AT: Assessing response to treatment of exacerbations of bronchiectasis in adults. Eur Respir J 2009, $33: 312-318$

\section{doi:10.1186/1745-6215-14-53}

Cite this article as: Chang et al:: Bronchiectasis exacerbation study on azithromycin and amoxycillin-clavulanate for respiratory exacerbations in children (BEST-2): study protocol for a randomized controlled trial. Trials 2013 14:53.

\section{Submit your next manuscript to BioMed Central and take full advantage of:}

- Convenient online submission

- Thorough peer review

- No space constraints or color figure charges

- Immediate publication on acceptance

- Inclusion in PubMed, CAS, Scopus and Google Scholar

- Research which is freely available for redistribution

Submit your manuscript at www.biomedcentral.com/submit
C Biomed Central 